\title{
Thorium-Based Thin Films as Highly Reflective Mirrors in the EUV
}

David D. Allred

allred@byu.edu

William R. Evans

Jed E. Johnson

Richard L. Sandberg

rudyskaboy@yahoo.com

R. Steven Turley

Follow this and additional works at: https://scholarsarchive.byu.edu/facpub

Part of the Astrophysics and Astronomy Commons, and the Physics Commons

\section{Original Publication Citation}

Jed E. Johnson, David D. Allred, R. Steven Turley, William R. Evans, and Richard L. Sandberg: "Thorium-Based Thin Films as Highly Reflective Mirrors in the EUV," in Actinides 26 -- Basic Science, Applications and Technology, edited by Sarrao, A. Schwartz, M. Antonio, P. Burns, R. Haire, H. Nitsche (Mater. Res. Soc. Symp. Proc. 893, Warrendale, PA, 26), 27-214 paper \# 893-JJ5-9.

\section{BYU ScholarsArchive Citation}

Allred, David D.; Evans, William R.; Johnson, Jed E.; Sandberg, Richard L.; and Turley, R. Steven, "ThoriumBased Thin Films as Highly Reflective Mirrors in the EUV" (2005). Faculty Publications. 986.

https://scholarsarchive.byu.edu/facpub/986

This Peer-Reviewed Article is brought to you for free and open access by BYU ScholarsArchive. It has been accepted for inclusion in Faculty Publications by an authorized administrator of BYU ScholarsArchive. For more information, please contact ellen_amatangelo@byu.edu. 


\title{
Thorium-Based Thin Films as Highly Reflective Mirrors in the EUV
}

\author{
Jed E. Johnson*, David D. Allred**, R. Steven Turley*, William R. Evans*, and Richard L. \\ Sandberg** \\ *Brigham Young University, **now Univ. of Colorado. \\ +allred@byu.edu; phone: (801)-422-3489; www.physics.byu.edu/faculty/allred/cv/05CV.htm
}

\begin{abstract}
As applications for extreme ultraviolet (EUV) radiation have been identified, the demand for better optics has also increased. Thorium and thorium oxide thin films (19 to 61 $\mathrm{nm}$ thick) were RF-sputtered and characterized using atomic force microscopy (AFM), spectroscopic ellipsometry, low-angle x-ray diffraction (LAXRD), x-ray photoelectron spectroscopy (XPS), and x-ray absorption near edge structure (XANES) in order to assess their capability as EUV reflectors. Their reflectance and absorption at different energies were also measured and analyzed at the Advanced Light Source in Berkeley. The reflectance of oxidized thorium is reported between 2 and $32 \mathrm{~nm}$ at 5,10, and 15 degrees from grazing. The imaginary component of the complex index of refraction, $\beta$, is also reported between 12.5 and $18 \mathrm{~nm}$. Thin films of thorium were found to reflect better between 6.5 and $9.4 \mathrm{~nm}$ at 5 degrees from grazing than all other known materials, including iridium, gold, nickel, uranium dioxide, and uranium nitride. The measured reflectance does not coincide with reflectance curves calculated from the Center for X-Ray Optics (CXRO) atomic scattering factor data. We observe large energy shifts of up to $20 \mathrm{eV}$, suggesting the need for better film characterization and possibly an update of the tabulated optical constants.
\end{abstract}

\section{INTRODUCTION}

Technological advances in recent years have increased the demand for the controlled use of higher energy radiation. The extreme ultraviolet (EUV) and soft x-ray portions of the electromagnetic spectrum $(\sim 0.5$ to $\sim 50 \mathrm{~nm})$ in particular have the potential for a number of important applications. Smaller computer chips could be fabricated using lithography techniques, which are presently limited by longer optical wavelengths. ${ }^{1}$ The biological community also recognizes the advantages of the EUV. Soft x-ray microscopy is promising because water is somewhat transparent below $4.4 \mathrm{~nm}$, whereas carbon's higher absorption helps resolve fine organic structures. ${ }^{2}$ Additionally, distant astronomical data could be analyzed more completely with increased reflection capabilities. ${ }^{3}$

Uranium has long been identified by researchers as an element which would theoretically exhibit high reflectance in this range because the deviation of the real part of its index of refraction from unity is significantly larger than any other element. Since the late 1990's, the BYU XUV Group has produced uranium-containing multilayers (U/Si specifically) and uranium compound films for space applications and theoretical reflectance verification. While it is still a promising material deserving of additional attention, there are critical issues which limit its practical effectiveness.

Uranium oxidizes readily. When exposed to air for only a matter of minutes, a fresh surface rapidly oxides to a depth of more than $10 \mathrm{~nm}$, changing the composition of the top 
portion of the thin film and dramatically lowering the EUV/soft x-ray reflectance. As lighter oxygen atoms are incorporated into the lattice structure, the uranium atoms that are most effective in reflecting high-energy light are pushed apart. Although this effect is fairly insignificant at optical wavelengths, the oxide becomes the dominant reflecting surface at higher energies. Moreover, uranium can pass through a number of oxidation states up to +6 , $\left(\mathrm{UO}_{3}\right)$. The depth and extent of this oxidation depends, among other things, on temperature and duration of ambient exposure. This leads to significant uncertainty in the composition of our films. ${ }^{4}$

This paper focuses on an alternative to uranium. Thorium is also a fairly stable radioactive metal but its half-life at 15 billion years is three times that of depleted uranium $\left({ }^{238} \mathrm{U}\right)$. However, its bulk density $\left(11.7 \mathrm{gm} / \mathrm{cm}^{3}\right)$ is considerably less than that of uranium $\left(19.3 \mathrm{gm} / \mathrm{cm}^{3}\right)$. Thus, even though the atomic scattering factors of Th and $\mathrm{U}$ are expected to be similar over most of the spectrum, the $\delta$ of Th metal should be considerably lower than that of $U$ metal due to the discrepancy in density. The quantity $\delta$ is the deviation of the refractive index from that of vacuum. The absorptive component of $n$ is termed $\beta$. The complex refractive index is thus defined as $n=1-\delta+i \beta$. Therefore, searches for high $\delta$ and $\beta$ do not turn up Th. ${ }^{5,6}$

However, in contrast to uranium, thorium cannot oxidize beyond the +4 oxidation state $\left(\mathrm{ThO}_{2}\right)$. Characterization and theoretical reflectance calculations are therefore less complex. Additionally, the density of $\mathrm{ThO}_{2}\left(9.86 \mathrm{gm} / \mathrm{cm}^{3}\right.$ bulk $)$ is comparable to that of $\mathrm{UO}_{2}$ $\left(10.96 \mathrm{gm} / \mathrm{cm}^{3}\right)$. The inevitable oxidation of the films helps to "level the playing field" between the two materials. ${ }^{4,7}$

\section{EXPERIMENTAL}

Samples were RF-magnetron sputtered in a thin film deposition system built at BYU. A four-inch target is mounted on a US Inc. sputter gun in a sputter-up geometry. The system, which employs copper gaskets, has been capable of ultrahigh vacuum pressures of less than $10^{-5} \mathrm{~Pa}$ when all incoming gas lines are leak free. A Ferran Scientific Millipole Analyzer (MPA) indicated a residual gas composition in the system after bake out consistent with that of a minute air leak. Analysis of samples using XPS (x-ray photoelectric spectroscopy), however, showed no significant nitrogen content. At the base pressure, only ambient oxygen at a partial pressure of about $2 \times 10^{-5} \mathrm{~Pa}$ was able to incorporate slightly into sputtered samples. The working gas under sputtering conditions was argon, and no substrate bias or heating was employed.

$\mathrm{ThO}_{2}$ thin films were reactively sputtered by flowing oxygen through a separate line into the chamber. Before igniting the plasma, the argon and oxygen flows were independently set so that oxygen would constitute about $20 \%$ of the gas atoms. The deposition rates of thorium and thorium oxide, respectively, were near 0.2 and $0.02 \mathrm{~nm} / \mathrm{sec}$. These rates were determined using a quartz-crystal thickness monitor in front of the shutter and slightly to the side. The diminished sputter rate in the case of $\mathrm{ThO}_{2}$ was due to substantial poisoning of the target surface.

Several different substrates were coated simultaneously so that the deposited films might be studied by multiple characterization techniques. These substrates included silicon wafer pieces, fused quartz slides, very thin polymer windows for transmission measurements, 
and carbon-coated TEM (transmission electron microscopy) grids. The substantial substrates, $\mathrm{Si}$ and quartz, were cleaned using standard methods to remove surface contaminants prior to the deposition. Silicon, because of its relatively low roughness $(>0.1 \mathrm{~nm}$ over a $100 \mathrm{~nm} \times 100$ $\mathrm{nm}$ area as measured by atomic force microscopy at our lab $)^{8}$, was used for reflection measurements where smoothness was important. The deposited films ranged from 10-60 nm in thickness. These measurements yield the absorption (imaginary) part, $\beta$, of the complex

refractive index in a very straightforward calculation from $T(\lambda) \approx T_{s}(\lambda) \chi e^{-\beta d}$, where $T_{s}(\lambda)$ is the transmission through polymer membrane, $d$ is the film thickness, and $\chi$ is the normal incidence reflection correction, which is approximately unity.

Since the tooling factor for our quartz-crystal monitor had not been measured, there were considerable uncertainties associated with using it to measure an absolute thickness. Instead, we fit LAXRD data to determine film thickness. A Scintag® X-ray diffractometer produced $\mathrm{Cu}-\mathrm{K} \alpha \mathrm{x}$-ray radiation incident on films at angles between 0.4 and 3 degrees from grazing. The reflectance maxima and minima were compared with the calculations of the modeling program $\mathrm{IMD}^{9}$ to determine the thickness of the film. No effort was made to slow the natural oxidation of the thin films. As a result, the initial LAXRD measurements were made on the sample within minutes of its removal from the deposition system. Measurements made over time on the thorium films showed an increase in thickness over time. This is consistent with previous experiments in which increasing thickness in uranium films was attributed to oxidation. The oxidation rate, however, is considerably less than that of uranium.

Depth-profile XPS was used to determine the composition of the samples at various positions in the film. As the film was sputtered through, an incident X-ray of known intensity was directed at the film. Depending on the measured energy of ejected electrons, the binding energies certain states can be calculated. The intensity and energy of these electrons determine relative elemental abundance.

Reflectance-wavelength scans between 2 and $32 \mathrm{~nm}$ at 5, 10, and 15 degrees from grazing, reflectance-angle scans between 0 and up to 85 degrees at selected wavelengths, and transmission scans between 2 and $32 \mathrm{~nm}$ (at and near normal) were obtained on beamline 6.3.2 at the Advanced Light Source (ALS) at Lawrence Berkeley National Laboratory (LBNL). More on normalization procedure can be found in reference 10.

Roughness measurements were conducted using AFM. Over a 100 by $100 \mathrm{~nm}$ area, the typical RMS roughness was found to be about $0.2 \mathrm{~nm}$, amounting to only a slight increase over typical substrate roughness. XANES (X-ray absorption near edge structure) spectra were also obtained at beamline 6.3.2. This involves measuring the current induced when photoelectrons are emitted by the sample due to the incident EUV beam.

\section{RESULTS}

Figure 1 shows the reflectance of a $38 \mathrm{~nm}$ thick thorium film as a function of wavelength at incident angles of 5, 10, and 15 degrees from grazing. As expected, reflectance decreases as the angle from grazing increases. The structure of the curve is essentially consistent between the 3 angles. There is a sharp dip in reflectance with smaller secondary peaks between about 12 to $16 \mathrm{~nm}$. Additionally, a small absorption edge is present at about $4.5 \mathrm{~nm}$ on the 5-degree curve. This is attributed to the presence of airborne carbon contaminants which have accumulated on the surface. 


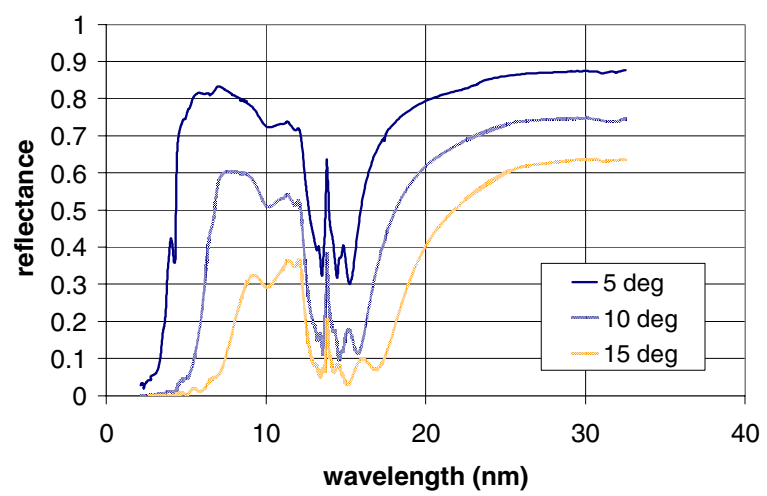

Fig. 1: Measured reflectance of a 38 $\mathrm{nm}$ thorium film as a function of wavelength at 5,10 , and $15 \mathrm{deg}$ from grazing.

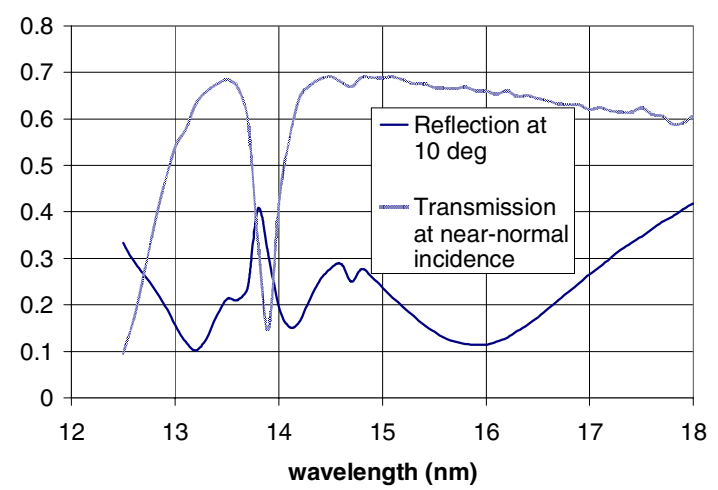

Fig. 2: Reflectance at 10 degrees from grazing and near-normal absorption as a function of wavelength of a $19.6 \mathrm{~nm}$ thorium film.

To verify the reflectance curve obtained in November 2003 (Fig. 1), a $19.6 \mathrm{~nm}$ thorium film was created and analyzed in March 2004. A transmission window was simultaneously coated during sputtering to provide additional absorption data. Fig. 2 shows these reflection and absorption curves plotted together. Prominent features, such as the spikes seen at close to $13.8 \mathrm{~nm}$ in both curves, indicate confidence and continuity in the data.

The imaginary part, $\beta$, of the complex index of refraction was calculated as a function of wavelength from the absorption data. Fig. 3 shows the absorption peak referred to in the previous paragraph. There is a dramatic increase in $\beta$ as the wavelength dips below $13 \mathrm{~nm}$. We have no reason to doubt the legitimacy of this data, as normalization should compensate for edge effects from beamline filters.

XANES measurements taken from both a naturally oxidized thorium film and a reactively sputtered $\mathrm{ThO}_{2}$ film are presented in Fig. 4. A uranium dioxide sample is also included to serve as a control and comparison. Immediately apparent is the dramatic difference in the two thorium curves. We are fairly confident in the high oxygen content of the thorium dioxide film because it is visibly transparent when reactively sputtered onto quartz. The degree of natural oxidation of the Th film, however, is unclear.

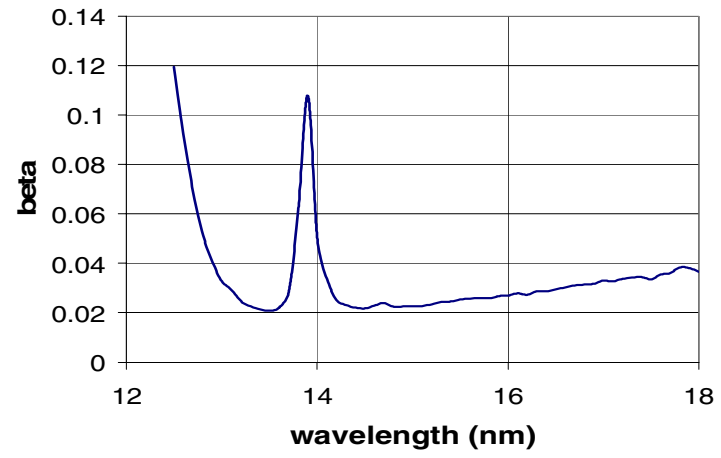

Fig. 3: Absorption coefficient beta as a function of wavelength, with approximation that $\chi=1$.

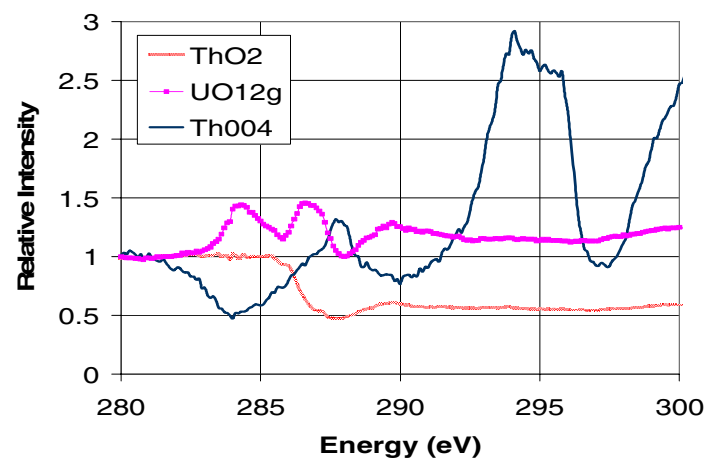

Fig. 4: XANES data of uranium dioxide, thorium dioxide, and oxidized thorium metal. 


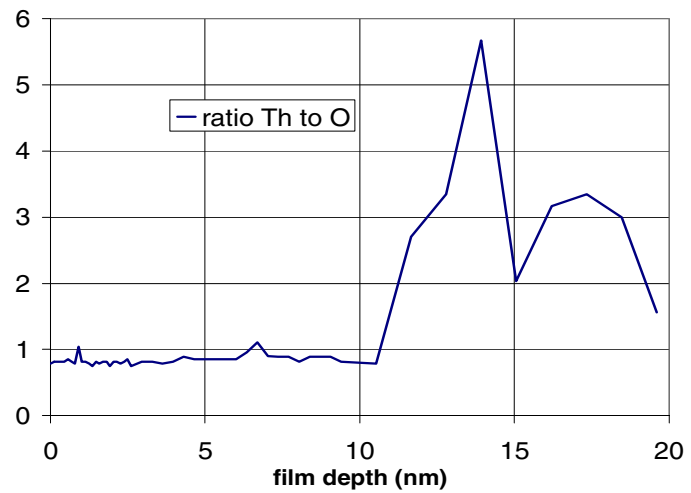

Fig. 5: XPS profiles the composition of the $19.6 \mathrm{~nm}$ film at various depths.

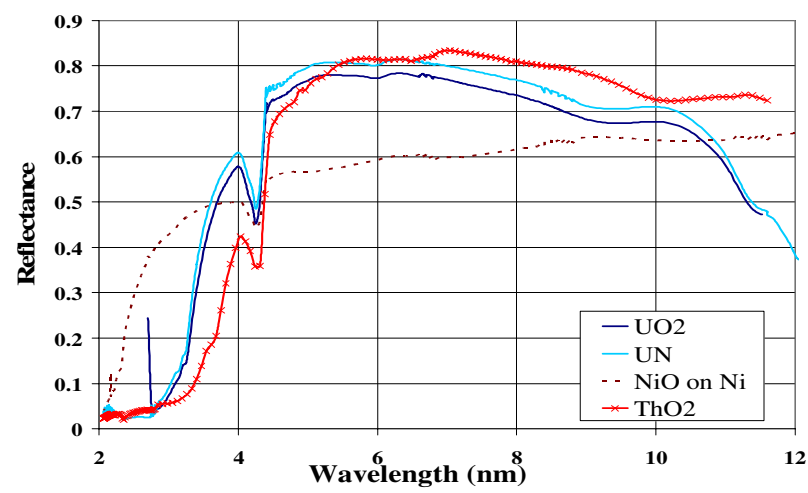

Fig. 6: Measured reflectance at 5 degrees from grazing of evaporated $\mathrm{NiO} / \mathrm{Ni}$, reactively sputtered $\mathrm{UN}$ and $\mathrm{ThO}_{\mathrm{x}}$ as a function of wavelength.

To learn more about the composition of this film, depth-profile XPS was performed and is presented in Fig. 5. The top half of the film has roughly an equal amount of both thorium and oxygen atoms. Since $\mathrm{ThO}_{2}$ is the only thermodynamically stable solid-oxide phase in the Th-O phase diagram, ${ }^{11}$ this can be interpreted as regions of thorium dioxide interspersed in the metallic thorium. However, rock-salt structure, metal-metalloid compounds $(\mathrm{M}-\mathrm{X}$, where $\mathrm{X}=\mathrm{C}, \mathrm{N})$ can exist in thin film form for the early transition metals (Ti, V, W, etc.) as well as for thorium and its neighbor, uranium. ${ }^{12}$ In these compounds, some oxygen can substitute for $\mathrm{C}$ or N. It is therefore possible that this film could actually be a metastable monoxide, particularly if there were $\mathrm{C}$ or $\mathrm{N}$ to stabilize it. ${ }^{11}$ More study is needed. While it would be intuitive to assume general similarity in the XANES curves of the two films, this is not the case. Lattice structure and elemental ratios presumably play a large role in this data.

\section{DISCUSSION}

Iridium, gold, and nickel are the current standard of reflectors in the EUV. A previous study was performed by the group which compared these materials to uranium nitride and uranium oxide. ${ }^{10}$ Fig. 6 shows reflectance data of thorium plotted against a sampling of those materials. From about 6.5 to $9 \mathrm{~nm}$, thorium exhibits higher reflectance than any material tested thus far.

We turn lastly to a comparison of our measured reflectance with a computed reflectance using optical constants available in the literature. ${ }^{13}$ Fig. 7 shows the 10-degree measured curve from Fig. 1 plotted alongside the computed curve. The x-axis has been re-defined in order to clearly see energy shifts between the two. While the overall shapes are remarkably consistent, the plots do not line up. There is a shift in energy (x-axis) of around $20 \mathrm{eV}$ in certain areas of the spectrum. As a consequence of this, specific energies with predicted reflectances in the neighborhood of $70 \%$ are as low as $10 \%(\sim 75 \mathrm{eV})$. 


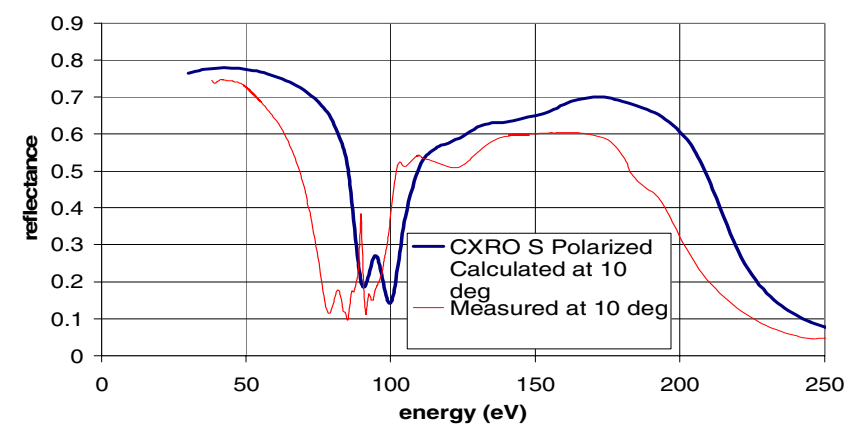

\section{Fig. 7: Measured (19.6 $\mathrm{nm}$ thick) and calculated Th reflectance at $10 \mathrm{deg}$. from grazing vs. energy (eV).}

There are two possible explanations. First, perhaps the current optical constants for elemental thorium are incorrect in this region. The thorium constants for this range as provided in ref 13 are not available in the open literature. They were received as a private communication from a researcher to the compilers of ref. 14. Thus, $\delta$ and $\beta$ of thorium may need to be remeasured.

There is a second possibility. It is necessary to ask whether the $\delta$ and $\beta$ of a compound like the film, whose reflectance is shown in Fig. 7, can really be calculated in the standard way employed in the x-ray range. At high energies, the optical constants of compounds, alloys, or mixtures are "computed." This is accomplished using atomic scattering factors (ASF) in essentially the same manner as $\delta$ and $\beta$ are computed for the elements. The ASF of each element is weighted with its atomic density in the compound and is multiplied by various constants. Chemical bonding effects are completely ignored. There also can be no shifts in the positions of absorption features. In the portion of the spectrum below the VUV, this approach does not work, as thorium dioxide is transparent in the visible (a few eV). Its optical constants at this energy are clearly not the sum of thorium's and oxygen's. This introduces a number of questions, namely what is true at $75 \mathrm{eV}$ ? Should we be using measured constants for the appropriate thorium-oxide compounds rather than constants computed from the constants of Th and $\mathrm{O}$ for calculations? And is it possible that at $75 \mathrm{eV}$, chemical shifts move absorption features by $15-20 \mathrm{eV}$ ? The absorption anomaly is around the Th $5 \mathrm{~d}$ threshold, but it is unclear whether an oxide would generate this large of an energy shift. Additional measurements need to be made.

Achieving a better understanding of the interaction between EUV radiation and thorium compounds requires better characterization of our mirrors. The rate and manner of oxidation in thorium thin films undeniably has a large effect on the optical properties of the metal. Presently, additional research is being performed in this area.

\section{CONCLUSION}

Thorium was found to be a viable alternative to conventionally-used reflectors in the EUV. Between 6.5 and $9 \mathrm{~nm}$, it reflected better at 5 degrees than any of the standard EUV coatings as well as uranium compounds. Such a material could enhance present technology as well as pioneer new ones. Notwithstanding, concerns such as film oxidation complicate characterization and alter reflectance. In the case of thorium, these issues are large enough to 
actually challenge previous scientific theory. Modifications to current models may be in order to more accurately explain the science behind EUV reflectance.

\section{ACKNOWLEDGMENTS}

We gratefully acknowledge the financial contributions of V. Dean and Alice J. Allred and Marathon Oil Company (formerly part of US Steel) for gifts to Brigham Young University for thin-film research. We thank all the members of the BYU EUV team for their support and measurements, including Mindy Tonks for AFM measurement of sample roughness, Niki Farnsworth for aiding in evaluating the importance of roughness to optical constant determination, and Winston Larsen for TEM. Moxtek provided the polymer substrates used for transmission measurements. We are grateful to Eric Gullikson and Andy Aquila at ALS beamline 6.3.2 at LBNL for their help in data interpretation, reduction, and analysis.

\section{REFERENCES}

1. http://www.research.ibm.com/journal/rd/411/chiu.html, June 5, 2004.

2. K. Takemoto, et al., "Transmission x-ray microscopy with $50 \mathrm{~nm}$ resolution in Ritsumeikan synchrotron radiation center,” X-ray Microscopy AIP Conference Proceedings 446-51 (2-6 Aug 1999).

3. D. D. Allred, M. B. Squires, R. S. Turley, W. Cash, and A. Shipley. "Highly reflective uranium mirrors for astrophysics applications," Proc. SPIE 4782, 212-223 (2002).

4. S. Lunt, "Determining the indices of refraction of reactively sputtered uranium dioxide thin films from 46 to 584 angstroms," M.S. Thesis (BYU, Provo, UT, 2000).

5. http://www.webelements.com/webelements/elements/text/Th/phys.html, Dec.27, 2005.

6. http://www.webelements.com/webelements/elements/text/U/phys.html, June 5, 2004.

7. http://www.processmaterials.com/oxides.html, June 7, 2004.

8. J. E. Johnson, "Thorium Based Mirrors for High Reflectivity in the EUV," Undergraduate Thesis (Brigham Young University, Provo, UT, 2004).

9. D. Windt, "IMD—-software for modeling the optical properties of multiplayer films," American Institute of Physics 12 (4), 360-370 (1998).

10. Richard L. Sandberg, David D. Allred, Shannon Lunt, Marie K. Urry, R. Steven Turley, "Optical Properties and Application of Uranium-based Thin Films for the Extreme Ultraviolet and Soft X-ray Region," in Optical Constants of Materials for UV to X-Ray Wavelengths," edited by Regina Soufli, and John F. Seely, Proceedings of SPIE, Vol. 5538, (SPIE, Bellingham, WA, 2004) 107-118.

11. J.F. Smith, O.N. Carlson, D.T. Peterson, and T.E. Scott, THORIUM: Preparation and Properties, $1^{\text {st }}$ ed. (The Iowa State University Press, Ames IA, 1975,) p. 324.

12. Edmund K. Storms, The Refractory Carbides, (Academic Press, New York, 1967).

13. http://www-cxro.lbl.gov/optical_constants, June 2004.

14. B.L. Henke, E.M. Gullikson, and J.C. David, "X-ray Interactions," Atomic Data and Nuclear Data Tables, 54(2), (1993) see ref 230 on p. 342. 